\title{
Leaf Traits and Histochemistry of Trichomes of Conocarpus lancifolius a Combretaceae in Semi-Arid Conditions
}

\author{
Amina Redha ${ }^{1}$, Naemah Al-Mansour ${ }^{2}$, Patrice Suleman ${ }^{3}$, Mohamad Afzal ${ }^{4}$, Redha Al-Hasan ${ }^{5}$ \\ Faculty of Science, Department of Biological Sciences, Kuwait University, Kuwait City, Kuwait. \\ Email: psuleman96@gmail.com
}

Received February $22^{\text {nd }}, 2011$; revised March 24 $4^{\text {th }}, 2011$; accepted March $28^{\text {th }}, 2011$.

\begin{abstract}
Leaf traits, structure and water status of Conocarpus lancifolius, a Combretaceae were investigated under semi-arid conditions. The leaf traits examined included leaf area and thickness, stomatal distribution, sclerophylly, succulence and relative water content. Additionally, the types of secretory structures, histochemistry of trichomes, and chemical nature of the cuticlular waxes were evaluated. Leaves showed xerophytic characteristics including a high degree of sclerophylly, thick cuticle and outer epidermal cell wall, low relative water content and high trichome density on younger leaves. The species has two types of trichomes; a secretory, short-stalked capitate trichome and a non-secretory trichome with a bulbous base and a pointed tip. The leaves also have a pair of extrafloral nectaries on both sides of the distal end of the petiole, 3 - 4 pairs near the leaf apex and two secretory ducts or cavities on mature leaves that secreted polysaccharides, epicuticlar waxes and polyphenols. Compared to young leaves mature leaves had almost 3 times total cuticular wax deposit or load. The most abundant fatty acids were palmitic, stearic, nondecanoic, behenic and arachidic acids. The leaf traits and structures are discussed in relation to semi-arid habitat.
\end{abstract}

Keywords: Leaf Morphology, Trichomes, Succulence, Sclerophylly, Cuticular Wax

\section{Introduction}

Most plants in arid and semi-arid conditions survive extreme environmental conditions by developing structures to tolerate their habitats. These plants commonly referred to as xerophytes have common features which include: small ratio of leaf area to volume $[1,2]$, a reduction in leaf cell size and number [3], thick cuticle and epidermal cell walls [2] and increased density in vascular tissues and sclerenchyma, which contribute to sclerophylly [4,5]. Xeromorphic leaves may be succulent, covered with trichomes and may develop water-storing cells. Xeromorphism however, is not limited to xerophytes and not all xerophytes develop xeromorphic features. Some plants that grow well in wet conditions have xeromorphic leaf features while others in dry habitats have mesomorphic characters [6]. Thus, leaf features partially explain how xerophytes thrive in arid habitats.

The plant species, Conocarpus lancifolius, was introduced into Kuwait as part of the "Greenery Program" and has turned out to be a "miracle ornamental plant" because it thrives extremely well under the semi-arid con- ditions.

C. lancifolius is Combretaceae (a family of trees, shrubs and lianas), a native plant on the coastal areas of Yemen, Somalia and Djibouti. In semi-arid conditions and sandy soils, it is a fast growing tree and produces large amounts of biomass particularly in the hot summer $\left(\geq 45^{\circ} \mathrm{C}\right)$ with drip irrigation. It can withstand a range of ambient temperatures $\left(15^{\circ} \mathrm{C}-50^{\circ} \mathrm{C}\right)$ but appears to be slightly frost sensitive. As an evergreen, it grows up to several meters in height with a single or multiple stems. Currently, no serious herbivores attack the species and it appears to be totally devoid of plant pathogens. Its adaptation or tolerance to abiotic and biotic factors is currently being investigated.

The species is vegetatively propagated from twigs, but two phenotypes or morphotypes of the species exists in the habitat: 1) plants with slightly gray, small green leaves and 2) those with larger glossy, dark green leaves. Phenotypes of this nature may be due to genotype differences or response to environmental conditions [7]. The existence of "silver and green" leaves within Cono- 
carpus erectus in islands of central Bahamas has been reported [8]. In semi-arid conditions, it appears C. lanciflolius may have morphological and structural adaptations to withstand low water potential.

Only a few studies have been conducted on C. lancifolius in particular and the genus, in general [8,9]. A high correlation was observed between drought, salinity and polyamine accumulation in Conocarpus lancifolius [9]. There has been no detailed characterization of the leaf morphology and structure of this species in any habitat.

The objective of this study was to examine the leaf traits C. lancifolius in semi-arid conditions. Additionally, we studied the histochemistry of trichomes, and composition of cuticular layer in order to understand their contribution to the species adaptation to a semi arid habitat.

\section{Materials and Methods}

\subsection{Leaf Morphology and Characteristics}

Young and mature leaf samples from 7-year-old trees were used for comparative study. Samples were taken from the same trees during the period of rapid growth in the summer. Leaf angle or orientation to the main axis was measured at mid-day during summer. Leaf morphology and structure were studied visually, with dissecting, light microscopes and scanning electron microscopy (SEM).

Additionally, the following leaf parameters were also measured: leaf area $\left(\mathrm{LA} ; \mathrm{cm}^{2}\right)$, measured with a portable leaf area meter (CI-203 CID Inc. Camas, WA USA), fresh weight (FW; g), fresh weight of fully saturated leaf (SFW; g) of leaves immersed for $48 \mathrm{~h}$ at $4^{\circ} \mathrm{C}$ in de-ionized water, dry mass (DW; g), after drying at $70^{\circ} \mathrm{C}$ to a constant weight. The sclerophyll index, leaf mass per unit area $\left(\mathrm{Sc}=\mathrm{DW} / \mathrm{LA} ; \mathrm{g} \cdot \mathrm{m}^{2}\right)$ and specific leaf area (SLA) was calculated as $\mathrm{m}^{2}$ leaf area per kg dry weight $\left(\mathrm{SLA}=\mathrm{m}^{2} \cdot \mathrm{kg}^{-1}\right)$. Leaf thickness (LT) was measured on the cross-sectional leaf cuts with scanning electron microscopy (SEM).

\subsection{Stomatal Characteristics}

Mature leaves were collected at midday and late in the evening to determine opened and closed guard cells. Stomatal distribution was determined on transpiring leaves by staining them with ethanol:crystal violet, $0.5 \%$ $(w / v)$ immediately after removal from plant. Leaf samples were preserved and processed for SEM. Both light and scanning electron microscopy (SEM) were used to determine stomatal density of both adaxial and abaxial surfaces.

Impressions of epidermal cells and stomatal complexes were made by applying clear nail polish on both the adaxial and abaxial surfaces of various leaves. The nail polish was removed and the number of stomata and type of stomatal complex were determined using a light microscope.

\subsection{Leaf Water Relations}

Leaves were harvested every 14 days in summer and the following leaf parameters were determined. The relative water content $(\mathrm{RWC}=(\mathrm{FW}-\mathrm{DW}) / \mathrm{SW}-\mathrm{DW}) \times 100$, leaf succulence $\left.\mathrm{Su}=(\mathrm{FW}-\mathrm{DW}) / \mathrm{LA} ; \mathrm{mg} \cdot \mathrm{H}_{2} \mathrm{O} \cdot \mathrm{cm}^{-2}\right)$ and leaf water content (LWC) was measured as a rough estimate of leaf density; (LWC =1 - DW/FW), [10].

\subsection{Leaf Structure and Histochemistry}

\subsubsection{Light Microscopy}

Leaves at different stages of development were used for bright field microscopy. Both cleared and fresh leaves were hand-sectioned. Clearing was done in glacial acetic acetic acid: $95 \%$ ethanol (1:3) and heated in an oven at $65^{\circ} \mathrm{C}$ until most of the pigments were removed. The leaves were then placed in $85 \%$ lactic acid and heated at $65^{\circ} \mathrm{C}$. Microtome sections were made from leaf tissues fixed in formaldehyde: glacial acetic acid: $70 \%$ ethanol $\operatorname{mix}(1: 1: 18 \mathrm{v} / \mathrm{v})$ and embedded in paraffin.

\subsubsection{Scanning Electron Microscopy (SEM)}

For SEM, leaves at various stages of development were fixed in glutaraldehyde, dehydrated in ethanol series, dried to the critical point with carbon dioxide and coated with gold. The samples were examined in a JEOL JSM-6300 SEM at $20 \mathrm{kV}$. Composition of secretory product of trichomes on fresh and gold coated leaf samples was carried out using LEO ZEISS, SUPRA 50 VP FESEM, (Carl Zeiss Nts, Oberkochen, Germany), voltage $15 \mathrm{kV}$, with Roentec's x-flash SDD detector (Roentec, Bruker's Berlin, Germany), and a energy-dispersive $\mathrm{x}$-ray spectroscope. Point analysis was done qualitatively and quantitatively with QuanTax 1.5 software.

\subsubsection{Histochemical Investigation}

The following histochemical tests were carried: Ruthenium Red for polysaccharides i.e. pectins and other mucilage other than cellulose [11]; Sudan 7B for suberin and cutin [12]; Sudan III for lipids; ferric chloride and vanillin $\mathrm{HCl}$ for phenolics [13,14]; Auramine O for cutin and suberin localization [15].

\subsection{Analysis of Cuticular Wax}

Leaf cuticle was analyzed for fatty acids that could contribute to resistance to stress factors. Cuticular wax was extracted from fresh young and mature leaves [16] using $5 \mathrm{~g}$ of leaf tissue. Extractions were carried out in triplicates. The extracts were evaporated under reduced pressure to $2 \mathrm{ml}$, dried under a stream of nitrogen and derivatized. 
The chemical constituents of each extract were analyzed using gas chromatography coupled with mass spectrometry (GC-MS DFS Thermo Finnigan, Breman, Germany). The TR-5 column $(30 \mathrm{~m} \times 0.25 \mathrm{~mm}$ i.d fused silica capillary column) from Thermo Electron Corp., Osterode, Germany, with helium as carrier gas was at $50^{\circ} \mathrm{C}$ for $3 \mathrm{~min}$, increased $6^{\circ} \mathrm{C} \cdot \mathrm{min}^{-1}$ up to $250^{\circ} \mathrm{C}$ and then to a final temperature of $300^{\circ} \mathrm{C}$ at $10^{\circ} \mathrm{C} \cdot \mathrm{min}^{-1}$. The individual component peaks and retention times were identified by comparing their MS with standards from Nist and Willey 275 database and quantified with XCaliber software.

\section{Results}

\subsection{Leaf Morphological Characteristics}

C. lancifolius leaves were simple, leathery, petiolate and arranged in pairs alternating with each other at an angle less than $180^{\circ}$. The mature leaf area was $7-28 \mathrm{~cm}^{2}$, glossy in appearance with relatively fewer trichomes on both surfaces. Leaves were amphistomatous with relatively same number of stomata on both adaxial and abaxial surfaces (Table 1). The stomata complex was anomocytic, with guard cells embedded in crypts formed by deposits of cuticular wax. Compared to mature leaves, younger and expanding leaves were glaucous, had slightly raised stomata, more trichomes and deposits of various crystalloids on their surfaces. Other leaf trait differences are shown in (Table 1).

\subsection{Leaf Water Relations, Sclerophylly and Succulence}

The leaf water status, sclerophylly and succulence data are shown in (Table 1). Sclerophylly was greater in mature leaves and leaf veins were relatively obscure on the adaxial surface of mautre leaves. The leaf RWC was between $82.4 \%-90.3 \%$ in the summer.

\subsection{Microscopy}

A cross section of the leaf showed a thick cuticular layer $(6-8 \mu \mathrm{m})$ and a thick adaxial epidermal cell wall. Beneath both epidermal tissues was a layer of hypodermal-like cells that stained positively for tannins and phenolic compounds. Mesophyll cells were interspersed with water storage cells and cells containing druses. Two types of trichomes were found on the leaf surfaces: a secretory and a non-secretory trichomes (Figures 1(a) and (b)). The non-secretory trichome was a long stalked cell with a bulbous base with a tapered end. The secretory trichome had capitate end with 4 pairs of cells and 3 - 4 stalked cells (Figure 2(a)). At the base of glandular trichome are secretory cells with dense cytoplasm and a few chloroplasts (Figure 2(b)). The developmental stages of this trichome are shown in (Figure 2(c)). Leaves turned glossier at maturity and the total number of trichomes declined. Trichome density on the abaxial surfaces was higher at all stages of leaf growth and development. The Fe-SEM point analysis of the secretory product from the short

Table 1. Leaf traits, morphology and water content of $C$. lancifolius.

\begin{tabular}{|c|c|c|}
\hline Leaf traits & Young leaf & Mature \\
\hline Leaf area $\left(\mathrm{cm}^{2}\right)$ & 8.9 & 22.4 \\
\hline Type of stomata & Anomocytic & Anomocytic \\
\hline $\begin{array}{l}\text { Stomatal density abaxial } \\
\left(\mathrm{mm}^{2}\right)\end{array}$ & nd & 132 \\
\hline $\begin{array}{l}\text { Stomatal density adaxial } \\
\left(\mathrm{mm}^{2}\right)\end{array}$ & nd & 144 \\
\hline Leaf thickness $(\mu \mathrm{m})$ & 132 & 150 \\
\hline Cuticle thickness $(\mu \mathrm{m})$ & 3.2 & 8.6 \\
\hline Leaf RWC (\%) & 81.2 & 85 \\
\hline Sclerophyll $\left(\mathrm{g} \cdot \mathrm{m}^{-2}\right)$ & 8 & 76.4 \\
\hline Succulence $\left(\mathrm{g} \cdot \mathrm{m}^{-2}\right)$ & 220 & 335.5 \\
\hline LWC & 1.1 & 1.65 \\
\hline Specified leaf area $\left(\mathrm{m}^{2} \cdot \mathrm{kg}\right)$ & 3.7 & 6.2 \\
\hline
\end{tabular}




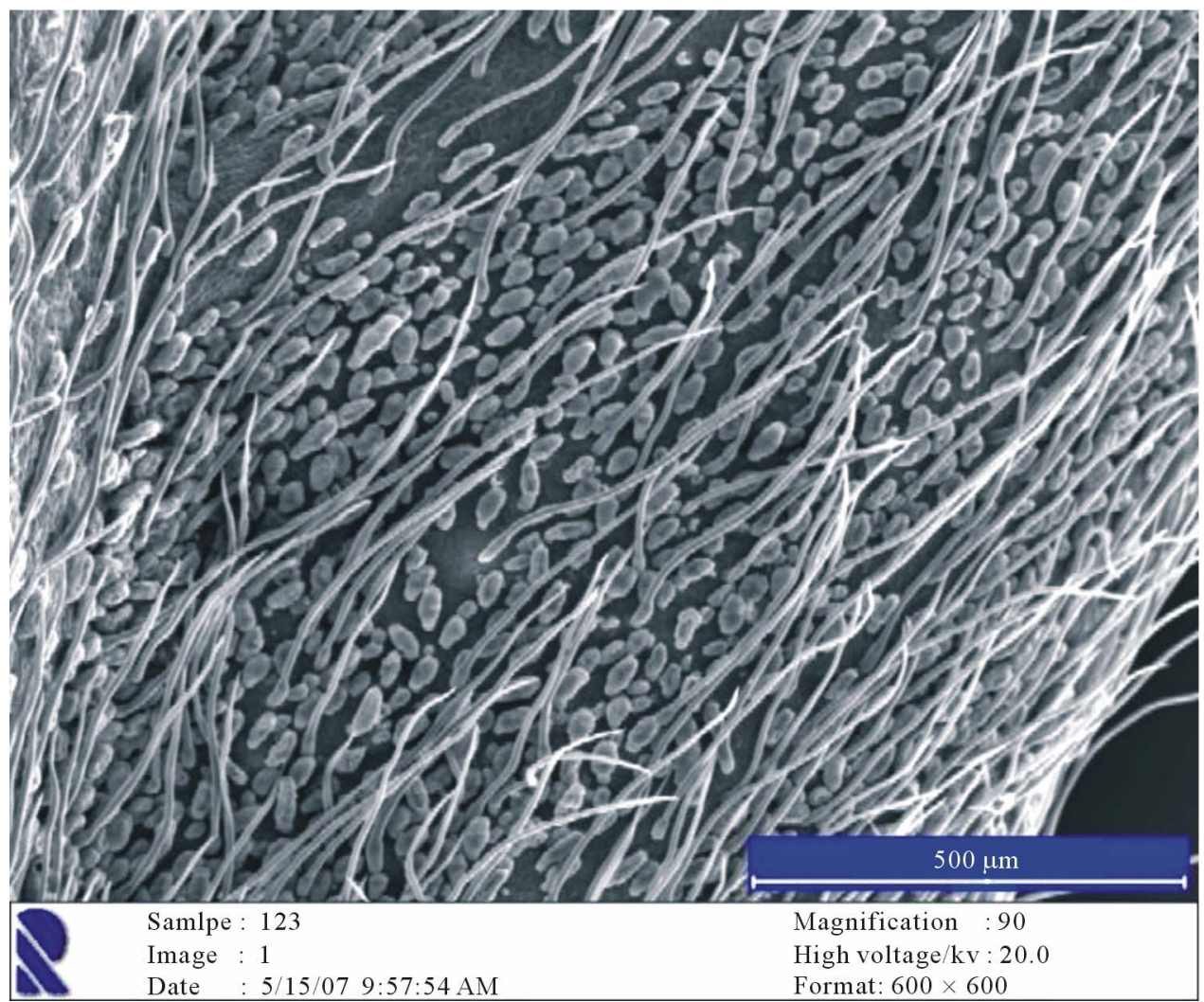

(a)

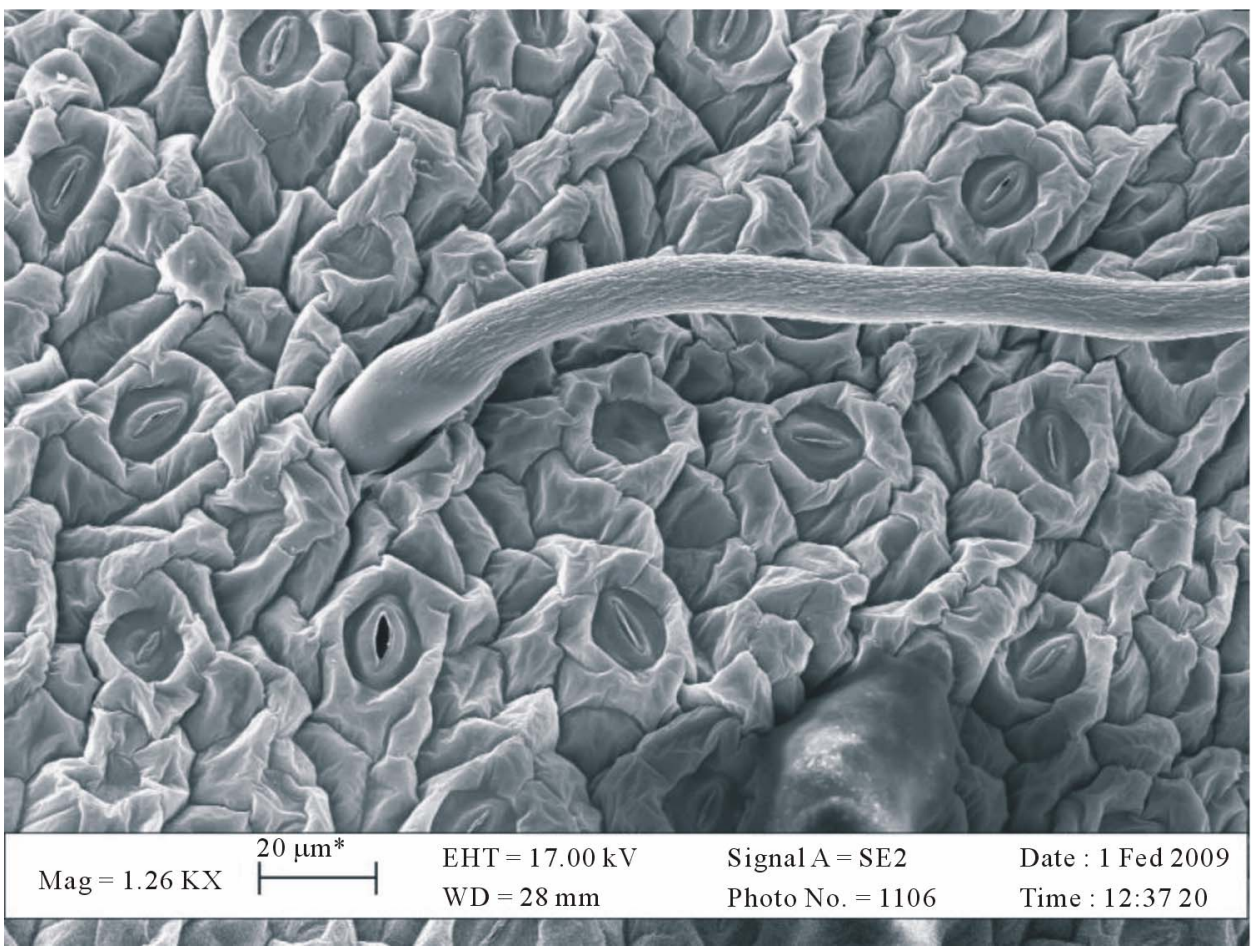

(b)

Figure 1. (a) SEM micrographs of secretory and non-secretory trichomes on a young leaf of C. lancifolius. (b) Stomata surrounded by cuticular wax and a basal portion of a long non-secretory trichome. 


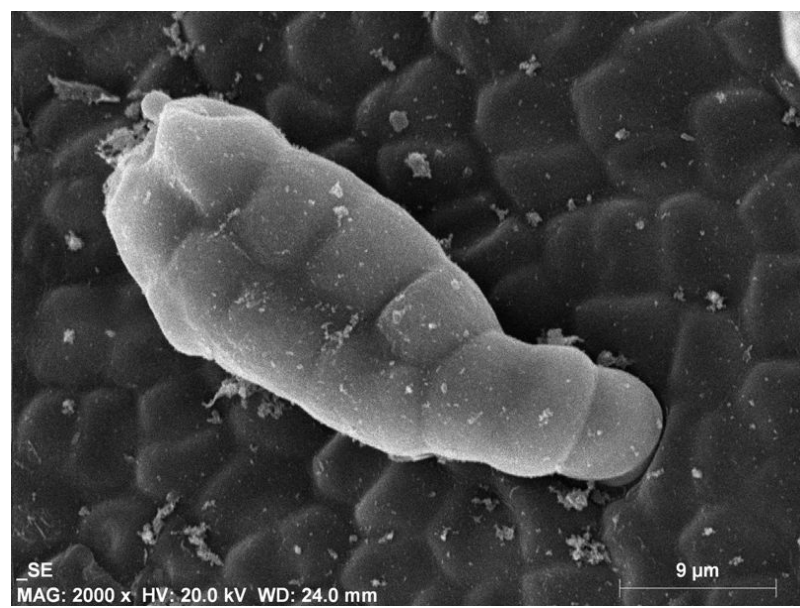

(a)

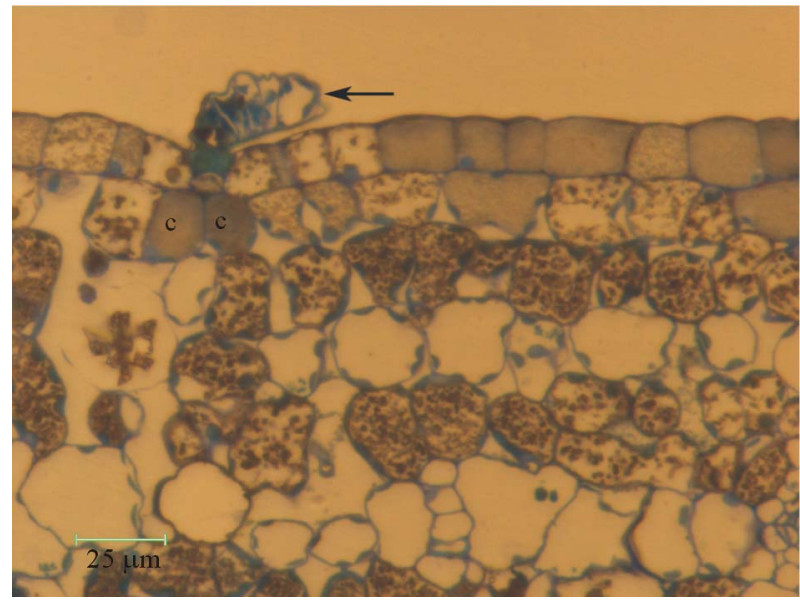

(b)

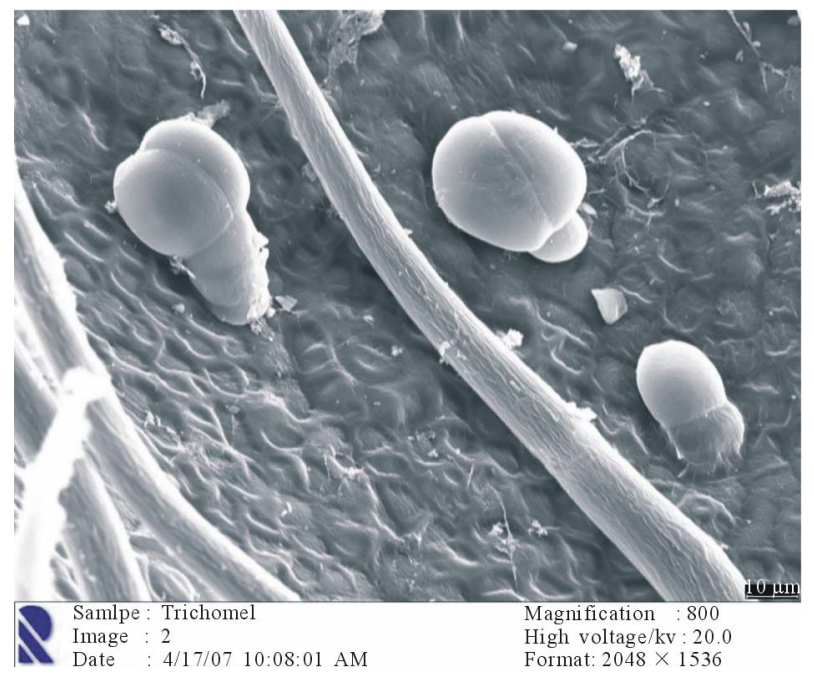

(c)

Figure 2. (a) SEM micrographs of secretory trichome of $C$. lancifolius. (b) Light microscopy of a section through a leaf and short-stalked secretory trichome (arrow) and secretory cells; “c”. trichome showed a high proportion of it was organic in nature. About $12 \%$ of it was phosphates and sulphates of magnesium, potassium and calcium (data not shown).

The distal end of leaf petioles had a pair of extrafloral nectaries and on the blade margins, 3-4 pairs near the leaf apex (Figures 3(a) and (b)).

As leaves matured, two secretory cavities develop on the adaxial surface. The first is a large, cavity located between the mid-vein and branch veins (Figures 4(a) and (b)). The cavity is surrounded by two layers of epithelial cells that secreted polysaccharides and other substances (Figure 4(c)). The second was smaller, dome-like structures along the mid-vein and randomly on the leaf blade. On the surface of these dome-like glands are sparsely distributed stomata. These glands ruptured or developed a single pore at the top to release secretory material, mostly epicuticlar waxes and phenolic compounds (Figure 5).

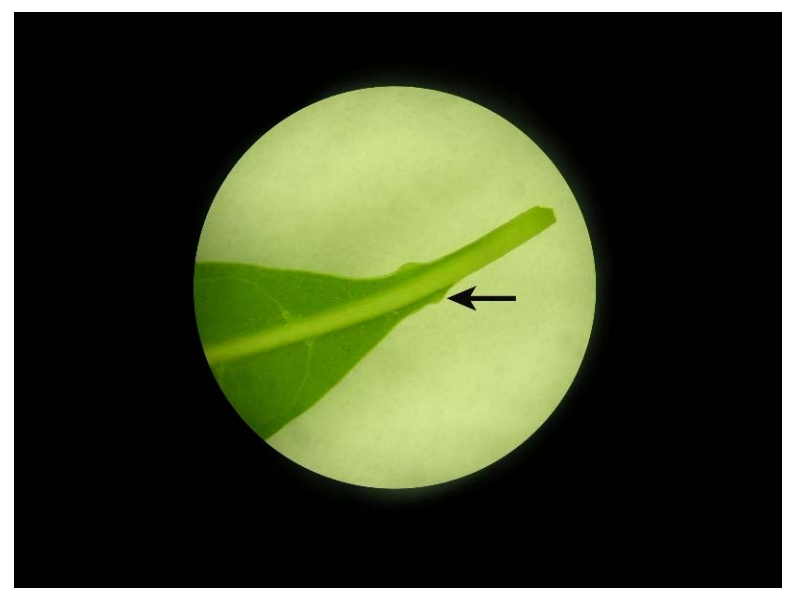

(a)

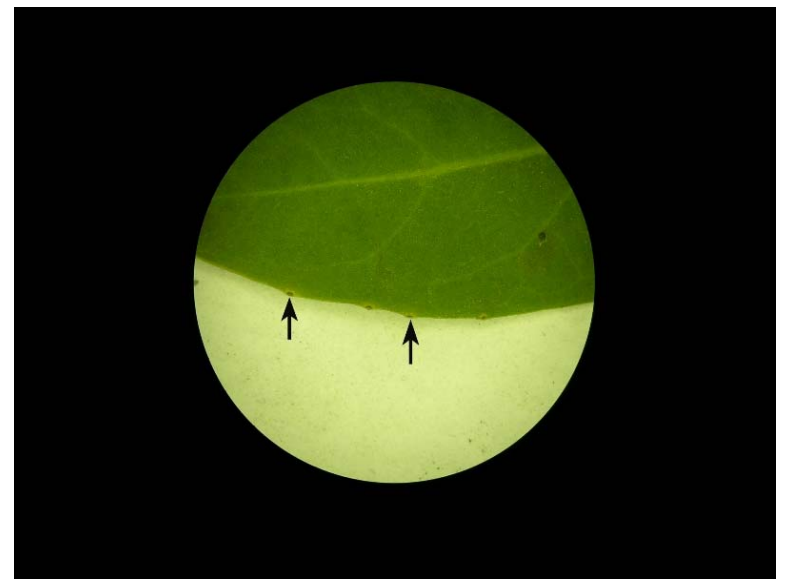

(b)

Figure 3. (a) Extrafloral nectaries on the petiole of $C$. Iancifolius leaf. (b) Extrafloral nectaries on the leaf margin near the leaf apex of $C$. lancifolius (arrows). 


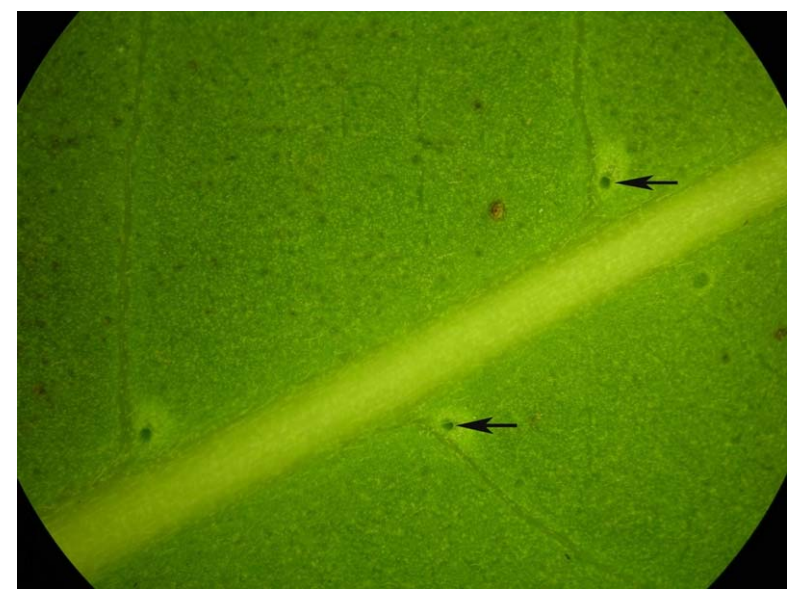

(a)

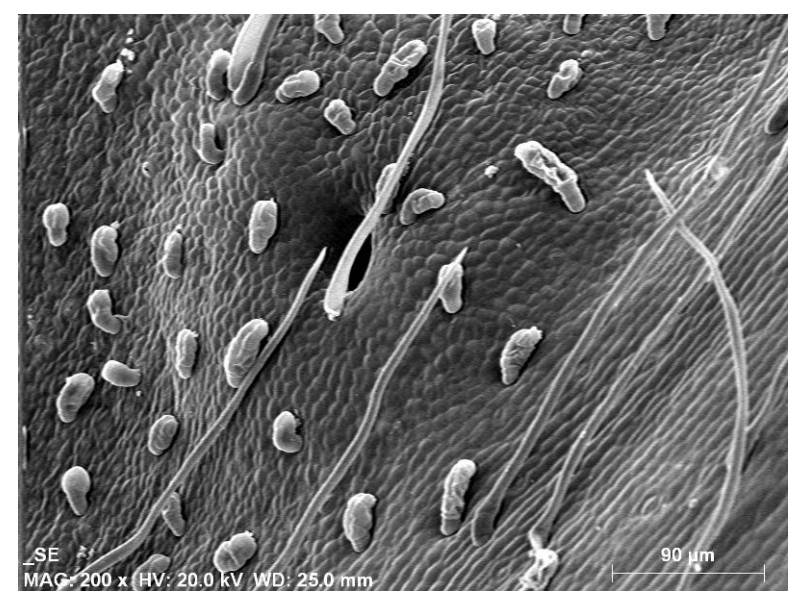

(b)

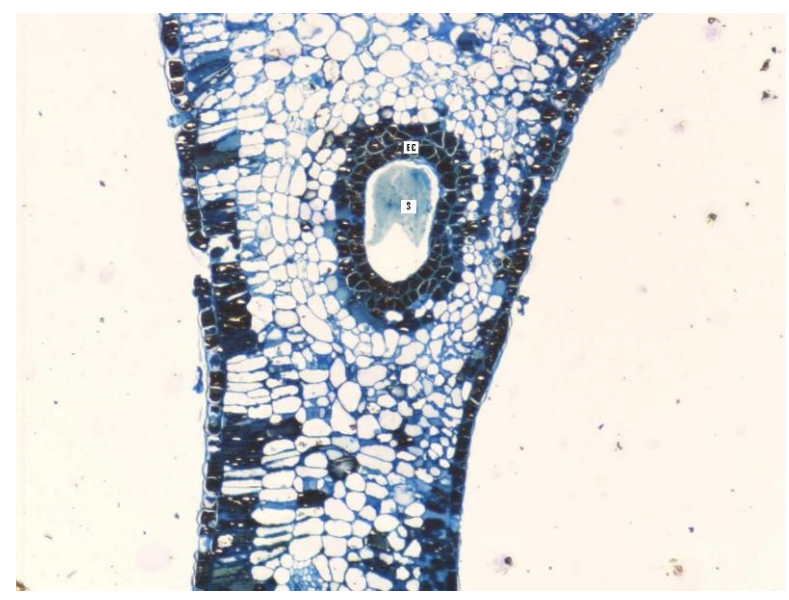

(c)

Figure 4. (a) Leaf surface showing secretory cavities. (a) Light micrograph of abaxial surface showing a hollow secretory cavities located between the mid-vein and branch veins (arrow) (×4). (b) SEM of a hollow secretory cavity. (c) Light micrograph of a section through a hollow secretory cavity; $\mathrm{EC}=$ epithelial cells and $\mathrm{S}=$ secretory substance (×10).

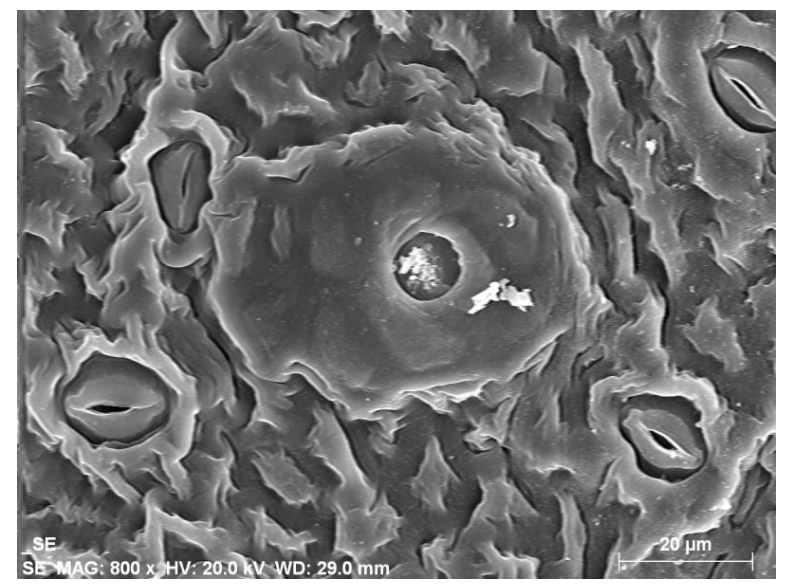

Figure 5. SEM of a pore of a collapsed dome-like secretory gland with secretions and scale-like platelets of cutin and waxes around it.

\subsection{Histochemistry}

Histochemical analysis of leaf tissues and trichomes with a number of stains showed the following positive results. Toluidine blue and Vanillin stained the epidermal and hypodermal cells shades of blue and reddish colors, respectively. Ferric chloride was positive for polyphenols and Ruthenium red showed the presence of polysaccharides other than cellulose. The capitate end and the bulbous base of trichomes stained red with Sudan III (Figure 6), an indication of the presence of lipids, waxes and terpenes. Sudan 7B and Auramine O turned the contents of the nectaries orange to red. Secreted material from extrafoliar nectaries on the petiole and leaf tips also turned reddish brown with Fehling's solution and brick red with Barfoed's test.

\subsection{Composition of Leaf Cuticular Waxes}

The major components of the cuticle were alkanes, fatty

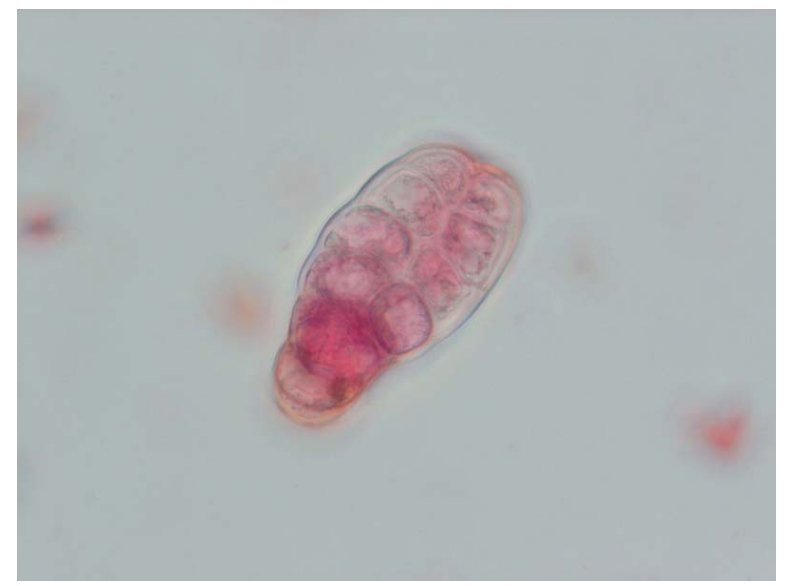

Figure 6. Bright field micrograph of short-stalked trichome with capitate head stained with Sudan III $(\times 10)$. 
acids and phenols. The composition of the cuticle was very similar in young, expanding and mature leaves (Figure 7). The alkanes comprised of $\mathrm{C}_{17}-\mathrm{C}_{32}$ chain lengths, the most abundant were pentamethylicosane $\left(\mathrm{C}_{20}\right)$, tetracosane $\left(\mathrm{C}_{24}\right)$, hexacosane $\left(\mathrm{C}_{26}\right)$, dotriacontane $\left(\mathrm{C}_{32}\right)$. Fatty acid methyl esters (FAME) detected in the wax are shown in Table 2. The predominant saturated fatty acids were palmitic acid and stearic acid although; nondecanoic acid, arachidic acid and behenic acid were found in significant amounts. The most prevalent phenolic compound was dimethylbenzylphenol.

\section{Discussion}

Plants that thrive in semi-arid habitats have adaptive features or mechanisms to mitigate extreme environmental factors such as water deficit [17] low nutrition [18] high

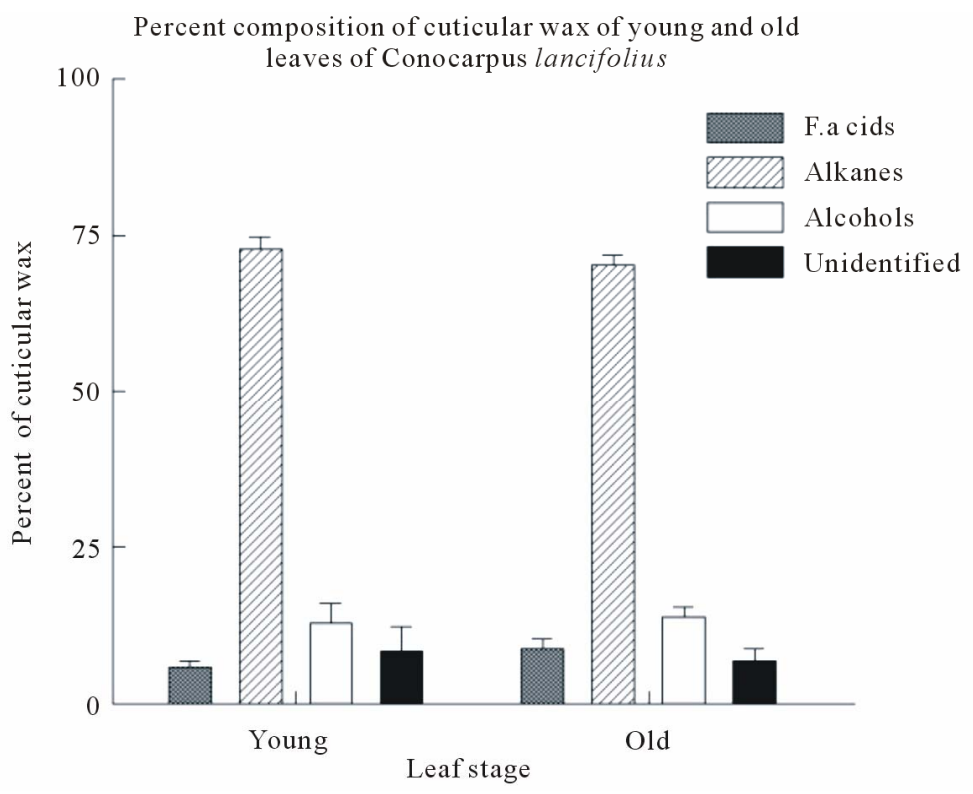

Figure 7. Percent composition of cuticular wax of young and old leaves of $C$. lancifolius.

Table 2. GC-MS analysis of fatty acid methyl esters extracted from cuticular layer of young and mature leaves of $C$. lancifolius.

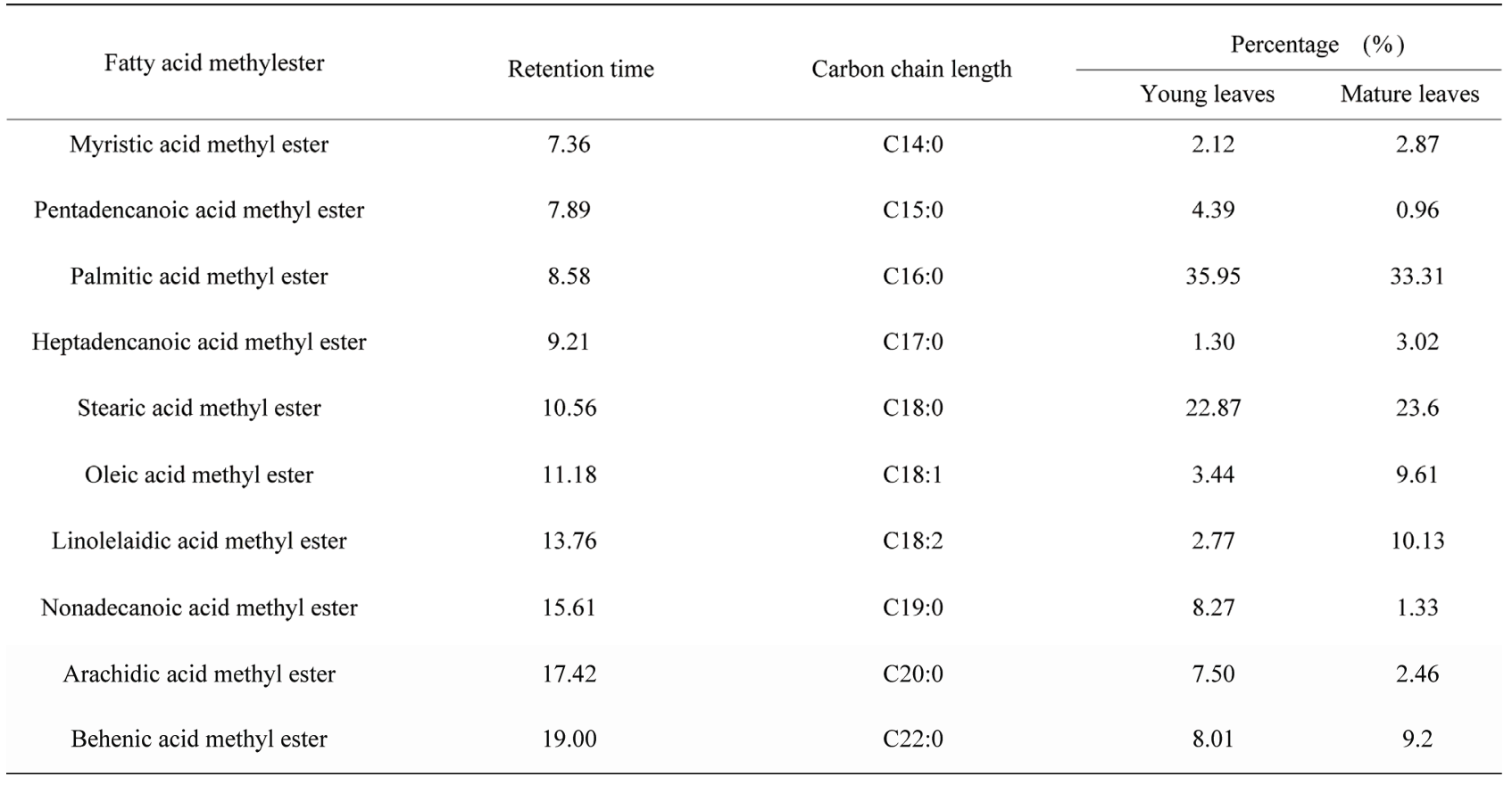


temperatures and solar radiation [19]. In this study leaf traits of C. lancifolius growing in semi-arid conditions showed xerophytic characteristics. These included a thick cuticle, thick adaxial epidermal cell wall and sclerophylly.

A few plants showed morphological differences similar to the polymorphism of Conocarpus erectus $[8,20]$. Apart from leaf area and color, these morphotypes had relatively the same leaf traits for young and matures leaves. It is possible that these phenotypic differences in C. lancifolius plants could be a response of individual plants to stress factors.

Mature leaves were also less glaucous and apparently did not lose their capacity for wax deposition. Wax deposit and/or composition restrict water loss and influence water permeability coefficient which in turn affects epidermal permeability and drought tolerance [21]. In this study, there was apparently no significant difference in the cuticular wax composition between young, expanding and mature leaves. Thus, it appeared the wax load coupled with adaxial epidermal wall thickness might be contributing to drought tolerance. In addition to restricting water loss from leaves, the epicuticlar waxes may serve to reflect excessive light thus, reducing the possibility of photoinhibiton [22-24]. The following leaf traits: leaf angle, stomata in depressions created by the cuticular wax deposits, thick outer epidermal cell wall with a thick cuticular layer could help reduce water loss.

The relative water content (RWC) was 82.4 - 90.3, this range of RWC values correlated with changes in tissue composition and some alterations in the relative rate of photosynthesis and respiration [25]. The range of sclerophylly was $57.1-83.2 \mathrm{~g} \cdot \mathrm{m}^{-2}$ and succulence of $289.4-$ $362.5 \mathrm{~g} \cdot \mathrm{m}^{-2}$ for mature leaves. Both parameters exceeded the $39 \mathrm{~g} \cdot \mathrm{m}^{-2}$ and $56 \mathrm{~g} \cdot \mathrm{m}^{-2}$ for sclerophylly and succulence respectively, recorded for mesomorphic leaves of deciduous trees and shrubs [5]. Sclerophylly in this habitat could be a consequence of drought stress [17] and/or the low nutrient-sandy soils [18].

Leaf surfaces had two types of trichomes: a secretory and a non-secretory trichome. The developing leaves and young leaf primodia had more trichomes per unit area than mature and fully expanded leaves [26,27]. The numbers of trichomes appeared to be established early during leaf differentiation and continued to increase with leaf growth $[26,28]$. During cell enlargement of leaves, no new trichomes were produced and those present became spatially distant from each other or were dropped. The short-stalked secretory trichome developed from epidermal initials. The high density of these trichomes may have a role in insulation and protection of young and expanding leaves.
Morphology and secretory characteristics of extrafloral nectaries are diverse in plants [29-31]. The only report of extrafloral nectaries on the genus Conocarpus is on Conocarpus erectus, on which a pair of nectatries on the petiole was described [29,31]. C. lanciflolius however, has three additional extrafloral nectaries, 3 - 4 pairs on margins near the leaf tip, a pair between the mid-vein and branch veins and randomly distributed dome-like secretory structures on the abaxial leaf surface.

Histochemically, the non-secretory trichome showed a positive reaction to Sudan 7B and Aoramine O, an indication of the presence of suberin-cutin in and on the cell wall. The reaction of sudan III showed the capitate head of the short trichomes contained lipids, waxes and terpenes, which may have protective functions [16]. Phenolic substances and some polysaccharides were detected by ferric chloride and Toliudine Blue in the epidermal cells and the cells contiguous to them. These phenolic compounds could deter herbivory and/or ameliorate the effect of the intense summer solar radiation. Fehling's and Bardfoed's tests on the secretory material from the nectaries on the petiole and leaf margins indicated the presence of reducing sugars and monosaccharides, respectively. These sugars probably attracted a number of beneficial insects that were observed on the plants particularly in summer.

Palmitic, stearic, nondecanoic, arachidic and behenic acids were detected in the wax of this species for first time and are among fatty acids methyl esters reported in the wax of some mangrove leaves $[32,33]$. The description of trichomes, extrafloral nectaries and phytochemical compounds which are adaptive features of species in arid environments, detected in the cuticle could serve as additional taxonomic characters.

The ecophysiological and biochemical studies that we have initiated may provide more insight in the species capacity to adapt to stress factors in a semi-arid habitat.

\section{Acknowledgements}

We thank Kuwait Foundation for the Advancement of Science (KFAS) for funding this project (\# 2007/1207/07), Research Administration, Kuwait University for partially funding this project (SL04/08) and the EM unit, KU for their assistance in microscopy. In addition, we thank Mrs. Jacquilion Jose and Mrs. Divya Saju who worked as Research Assistants on this project.

\section{REFERENCES}

[1] G. Karabourniotis and J. Bornman, "Penetration of UV-A, UV-B and Blue Light through the Leaf Trichome Layers of Two Xeromorphic Plants, Olive and Oak, Measured by Optical Fibre Microprobes," Physiologia Plantarum, Vol. 
105, No. 4, 1999, pp. 655-661. doi:10.1034/j.1399-3054.1999.105409.x

[2] A. G. Richardson and G. Berlyn, "Changes in Foliar Spectral Reflectance and Chlorophyll Fluorescence of Four Temperate Species Following Branch Cutting," Tree Physiology, Vol. 43, 2002, pp. 499-506.

[3] K. Chartzoulakis, A. Bosabalidis, A. Patakas and A. Vemmos, "Effect of Water Stress on Water Relation, Gas Exchange and Leaf Structure of Olive Tree," Acta Horticulturae, Vol. 537, 2000, pp. 241-247.

[4] C. Edwards, J. Read and G. Sanson, "Characterizing Sclerophylly: Some Mechanical Properties of Leaves from Heath and Forest," Oecologia, Vol. 123, No. 2, 2000, pp. 158-167. doi:10.1007/s004420051001

[5] F. Bussoti, D. Bettini, P. Grossoni, R. Mansuino, C. Soda and C. Tani, "Structure and Functional Traits of Quercus Ilex in Response to Water Availability," Environmental Experimental Botany, Vol. 47, No. 1, 2002, pp. 11-23. doi:10.1016/S0098-8472(01)00111-3

[6] K. Esau, "Anatomy of Seed Plants," John Wiley and Sons, New York, 1997.

[7] K. Kathiresan and B. L. Bingham, "Biology of Mangrove and Mangrove Ecosystems," Advance Marine Biology, Vol. 40, 2001, pp. 81-251. doi:10.1016/S0065-2881(01)40003-4

[8] T. W. Schoener, "Leaf Damage in Island Buttonwood, Conocarpus Erectus: Correlations with Pubescence, Island Area, Isolation and Distribution of Major Carnivores," Oikos, Vol. 53, 1988, pp. 253-266. doi: $10.2307 / 3566071$

[9] A. Manal, A. Redha and P. Suleman, "Polyamine Accumulation and Osmotic Adjustment as Adaptive Response to Water and Salinity Stress in Conocarpus Lanciflolius," Functional Plant Science and Biotechnology, Vol. 3, 2009, pp. 42-48.

[10] E. Garnier and G. Laurent, "Leaf Anatomy, Specific Mass and Water Content in Congeneric Annual and Perennial Grass Species," New Phytologist, Vol. 128, No. 4, 1994, pp. 725-736. doi:10.1111/j.1469-8137.1994.tb04036.x

[11] W. A. Jensen, "Botanical Histochemistry: Principles and Practice," Freeman, San Francisco, 1962.

[12] M. C. Brundrett, B. Kendrick and C. A. Peterson, "Efficient Lipid Staining in Plant Material with Sudan 7B or Fluorol Yellow 088 in Polyethylene Glycol-Glycerol," Biotechnic and Histochemistry, Vol. 66, 1991, pp. 111116. doi:10.3109/10520299109110562

[13] P. B. Gahan, "Plant Histochemistry and Cytochemistry," Academic Press, London, 1984.

[14] C. O. Mosjidis, C. M. Peterson and J. A. Mosjidis, "Developmental Differences in the Location of Polyphernols and Condensed Tannins in the Leaves and Stems of Sericea Lespedeza, Lespedeza Cuneata," Annals of Botany, Vol. 65, 1990, pp. 355-360.

[15] Y. Heslop-Harrison and J. Heslop-Harrison, "The Digestive Glands of Pinguicula: Structure and Cytochemistry," Annals of Botany, Vol. 47, 1981, pp. 293-319.
[16] G. T. Wagner, "Secreting Glandular Trichomes: More than Just Hairs," Plant Physiology, Vol. 96, No. 3, 1991, pp. 675-679. doi:10.1104/pp.96.3.675

[17] J. J. Oertli, S. H. Lips and M. Agami, "The Strength of Sclerophyllous Cells to Resist Collapse Due to Negative Turgor Pressure," Acta Oecologia, Vol. 11, 1990, pp. 281-289.

[18] N. C. W. Beadle, "Soil Phosphate and Its Role in Molding Segments of Australian Flora and Vegetation with Reference to Xeromorphy and Sclerophylly," Ecology, Vol. 47, No. 6, 1966, pp. 992-1007. doi: $10.2307 / 1935647$

[19] G. Jordan, R. A. Dillon and P. H. Weston, "Solar Radiation as a Factor in the Evolution of Scleromorphic Leaf Anatomy in Proteaceae," American Journal of Botany, Vol. 92, No. 5, 2005, pp. 789-796. doi:10.3732/ajb.92.5.789

[20] A. A. Agrawal and D. A. Spiller, "Polymorphic Buttonwood: Effects of Disturbance on Resistance to Herbivores in Green and Silver Morphs of a Bahamian Shrub," American Journal of Botany, Vol. 91, No. 12, 2004, pp. 1990-1997. doi:10.3732/ajb.91.12.1990

[21] J. Y. Zhang, C. D. Broeckling, E. B. Bancafllor, M. K. Sledge, L. W. Sumner and Z. Y. Want, "Overexpression of WXP1, a Putative Medicago Truncatula AP2 Domain-Containing Transcription Factor Gene, Increases Cuticular Wax Accumulation and Enhances Drought Tolerance in Transgenic Alfalfa (Medicago Sativa)," Plant Journal, Vol. 42, No. 5, 2005, pp. 689-707. doi:10.1111/j.1365-313X.2005.02405.x

[22] C. Neinhuis, K. Koch and W. Barthlott, "Movement and Regeneration of Epicuticular Waxes through Plant Cuticles," Planta, Vol. 213, No. 3, 2001, pp. 427-434. doi: $10.1007 / \mathrm{s} 004250100530$

[23] M. G. Holmes and D. R. Keiller, "Effects of Pubescence and Waxes in the Reflectance of Leaves in the Ultraviolet and Photosynthetic Wavebands: A Composition of a Range of Species," Plant Cell and Environment, Vol. 25, No. 1, 2002, pp. 85-95. doi:10.1046/j.1365-3040.2002.00779.x

[24] K. Kock, C. Neinhius, H. J. Ensikat and W. Barthlott, "Self Assembly of Epiculticular Waxes on Living Plant Surfaces Imaged by Atomic Force Microscopy (AFM)," Journal of Experimental Botany, Vol. 55, No. 397, 2004, pp. 711-718. doi:10.1093/jxb/erh077

[25] L. Gonzàlez and M. Gonzàalez-Vilar, "Determination of Relative Water Content," In: M. J. R. Roger, Ed., Handbook of Plant Ecophysiology Techniques, Kluwer Academic Publishers, Dordrecht, 2001, pp. 207-212.

[26] E. Werker, E. Putievsky, U. Ravid, N. Dudai and I. Katzir, "Glandular Hairs and Essential Oil in Developing Leaves of Ocimmum Basilicum L. (Lamiaceae)," Annals of Botany, Vol. 71, No. 1, 1993, pp. 43-50. doi:10.1006/anbo.1993.1005

[27] T. M. Bourett, R. J. Howard, D. P. O'keefe and D. L. Hallahan, "Gland Development on Leaf Surfaces of $\mathrm{Ne}$ peta Racemosa," International Journal of Plant Science, 
Vol. 155, No. 6, 1994, pp. 623-632. doi: $10.1086 / 297202$

[28] L. Ascensao and M. S. S. Pais, "Glandular Trichomes of Artemisa Campestris (Ssp. Maritima): Ontogeny and Histochemistry of the Secretory Product," Botanical Gazette, Vol. 148, No. 2, 1987, pp. 221-227. doi: $10.1086 / 337650$

[29] T. S. Elias, "Extrafloral Nectaries: Their Structure and Distribution," In: B. Bentley and T. Elias, Eds., The Biology of Nectaries, Columbia University Press, New York, 1983, pp. 174-203.

[30] A. Fahn, "Secretory Tissues in Vascular Plants," New Phytologist, Vol. 108, No. 3, 1988, pp. 229-257. doi:10.1111/j.1469-8137.1988.tb04159.x
[31] S. Koptur, "Plants with Extrafloral Nectatries and Ants in Everglades Habitats," Florida Entomologist, Vol. 75, 1992, pp. 39-50. doi:10.2307/3495479

[32] S. Misra, A. K. Datta, S. M. Chattopadhyay, A. Choudhury and A. Ghosh, "Hydrcarbons and Wax Esters from Seven Species of Mangrove Leaves," Phytochem, Vol. 26, 1987, pp. 3265-3268. doi:10.1016/S0031-9422(00)82484-X

[33] T. J. Walton, "Waxes, Cutin and Suberin,” In: J. L. Harwood and J. Boyer, Eds., Methods in Plant Biochemistry, Vol. 4, 1990, pp. 106-158. 